\title{
The Model of Logistic Chains in the Arctic Zone Conditions in Industry 4.0
}

\author{
Ekaterina Afonichkina \\ Institute of Industrial Management, \\ Economics and Trade \\ Peter the Great St.Petersburg \\ Polytechnic University \\ St.Petersburg, Russia \\ ekaterinaafonichkina@gmail.com
}

\author{
Aleksandr Afonichkin \\ Institute of. Economics and \\ Management \\ Samara University \\ (of Affiliation) \\ Samara, Russia
}

\author{
Nikolay Didenko \\ Institute of Industrial Management, \\ Economics and Trade \\ Peter the Great St.Petersburg \\ Polytechnic University \\ St.Petersburg, Russia \\ didenko.nikolay@mail.ru
}

\begin{abstract}
The problem of modeling and forming the value chains in the Arctic zone, which has some critical features, is considered in Industry 4.0. A rationale for concepts and a review of approaches to modeling the business chains is given, a systematization of groups of business chains is carried out, and their characteristics are given. It is proposed to consider the Arctic economic zone, for development purpose, as a complex of value chains that form different values in the areas of production, mining, logistics, social sphere, etc.
\end{abstract}

A generalized model of the logistic chain is described in detail, a description of the parameters is given, and the efficiency of the entire chain is evaluated, considering the local effectiveness of the chain participants. To ensure marginal efficiency, the task of managing the structure (composition) of the logistics chain is considered, which allows participants to vary in terms of their functionality, resource support and level of local efficiency, considering the synergy of interaction in the chain structure.

Keywords- Arctic zone, economic system, value chains, logistics chains, supply chain model, management of the chain structure

\section{INTRODUCTION}

Modern development of the economic space of the Arctic requires the use of sustainable development management technologies which take into consideration environmental requirements and norms that reflect the concept of sustainable development. Along with production and mining enterprises and technological processes [1], an important element of development policy in this area are the logistic processes which include the supply of production and population, interaction between participants in supply chains, etc. [2-4]

In this regard, for the effective development of the Arctic zone, it is necessary to form a well-thought-out logistic chain that would be part of a single vector of strategic development of the Arctic, taking into account the risks associated with the development of the territories of the Arctic zone, the requirements of ecology and social projects for indigenous people. [5,6] The existing experience of developing the Arctic territories of circumpolar countries shows $[7,8]$ the need for high costs for the formation of infrastructure, also logistics. In addition, the achievement of high efficiency of the process of development of the Arctic requires:

- close cooperation of interested economic entities, including those involved in logistics chains,
- availability of the required resource development potential for the formed chains,

- one of the leading resources for the development of the Arctic in Industry 4.0 is the information - operational, strategic, forecast, as well as information about the dynamics of climate development, ecology, the use of natural resources, production activities and the building up the logistic schemes,

- the amount of financing necessary for ensuring its own operational processes for each chain participant,

- a clearly developed and agreed plan-budget of the activity of the logistic chain.

Only joint and coordinated actions of each participant in the supply chain, the overall concentration of resources and opportunities, the required size of the investment and economic development potential can lead to positive results and have a positive effect for the entire supply chain, and therefore the income for each participant in such a chain.

However, despite the presence of high opportunities for the economic development of the Arctic, the economic prospects for such development are in their infancy and are not yet taken into consideration in the strategy of the Arctic development, although the result could have enormous growth potential.

This is explained by the fact that the development of the Arctic international territories requires the solution of complex problems not only in the basic processes of production and extraction, processing of resources, but also better organization of information, transport support, logistics and other logistical tasks.

A particularly important resource in the Arctic zone is the time factor, due to the possible rapid climate change, which can create significant logistics organization problems. In this regard, the update, accuracy and completeness of information on the dynamics of processes in the Arctic may reduce the risks of the development of the Arctic zone. To do this, it is necessary to form a distributed database of information (Big Data) by each individual participant in the Arctic process on the issues of their operating activities. This is possible with the use of powerful distributed resources of Industry 4.0 technologies, involving the implementation of digital technologies. This requires the interaction of the type of information provided, the methodology of transformation, 
storage procedures, information security. The effectiveness of a business chain without information interaction of its participants can be significantly reduced. This is one of the important conditions for the formation of the efficiency of business chains.

Risk assessment of production and mining activities, transport logistics and ecology are considered in the books [9-11]. Expansion of international cooperation in the field of production, information and logistics, the creation of international logistics chains will contribute to improving the development of the Arctic zone.

\section{BUSINESS CHAINS. MODELS AND SYSTEMATIZATIONOF THEIR MODELING APPROACHES}

In accordance with the concept of value chain developed by M. Porter [12], business processes are divided into two groups:

- the main (primary) business processes that form the complex of consumer values. M. Porter includes in this group: inbound logistics, operations, outbound logistics, marketing and sales, services;

- supporting (support activities, secondary) business processes that do not directly create value but are necessary for the functioning of the main business processes. M. Porter classifies them as: - procurement; - technological development; - human resource management; - maintaining the infrastructure of the company.

Later, in some papers, an addition to these basic business processes is provided, which gives more detailed identification of management and development functions. In particular, the basic processes are complemented by the following: - management processes, - development processes.

When summarizing groups of business processes, their characteristics can be systematize as following (Table 1).

TABLE I. SYSTEMATIZATION OF CHARACTERISTICS OF BUSINESS PROCESSES GROUPS

\begin{tabular}{|l|l|l|}
\hline $\begin{array}{c}\text { Business } \\
\text { processes } \\
\text { group }\end{array}$ & $\begin{array}{c}\text { Purpose of the business } \\
\text { process }\end{array}$ & \multicolumn{1}{|c|}{$\begin{array}{c}\text { The results of } \\
\text { operations of the } \\
\text { business process }\end{array}$} \\
\hline Main & Creating customer value & $\begin{array}{l}\text { Final or intermediate } \\
\text { value of the } \\
\text { consumer }\end{array}$ \\
\hline Supporting & $\begin{array}{l}\text { Providing all kinds of } \\
\text { resources of the main and } \\
\text { other business processes }\end{array}$ & $\begin{array}{l}\text { Production and } \\
\text { management } \\
\text { resources for all } \\
\text { types of business } \\
\text { processes }\end{array}$ \\
\hline Management & $\begin{array}{l}\text { Management and } \\
\text { organization of all types } \\
\text { of business processes }\end{array}$ & $\begin{array}{l}\text { Formation of control } \\
\text { actions for making } \\
\text { management } \\
\text { decisions in all types } \\
\text { of } \\
\text { processes }\end{array}$ \\
\hline
\end{tabular}

\begin{tabular}{|l|l|l|}
\hline Development & $\begin{array}{l}\text { Sustainable and balanced } \\
\text { development through the } \\
\text { coordination of interests } \\
\text { of participants in } \\
\text { business processes }\end{array}$ & $\begin{array}{l}\text { Organizational and } \\
\text { production changes } \\
\text { for a balanced } \\
\text { growth a } \\
\text { participants and } \\
\text { directions of } \\
\text { business processes, } \\
\text { through improving } \\
\text { the efficiency of the } \\
\text { network of business } \\
\text { processes }\end{array}$ \\
\hline
\end{tabular}

All specified business processes should be formalized and described in detail for the effective operation of economic systems. Here is a brief description of possible approaches for the description and modeling of business processes.

In the paper [14], a generalization of approaches to the description of value chains is given. The reference (typical) and individual business processes are identified. For modeling of those two types different approaches are used.

So, for the formation of reference models of business processes, one can use the following approaches:

- universal Business Model (OBM) by Oracle;

- 8-process mode BKG;

- 13-process model - ISO/IEC/TO 15504;

- APQC model; quality management standard model ISO 9000:2000.

In addition, there are ready-made typical industry models of business processes, for example, for banks, manufacturing enterprises [13], etc.). The advantages of such models are:

- reducing the cost of creating a business model, since standardized process representations are used,

- the possibility of acquiring process models together with a business modeling system, which requires only refinement and adaptation of the reference model.

For modeling non-standard (single) business processes, the following approaches are commonly used: functional approach, when the analysis and selection of business processes is carried out based on the functions performed by the participants of the business chain; product approach, highlighting the processes based on their results (specific goods and services producing in the value chain; an approach based on the analysis of value chains; matrix approach, which is characterized by a matrix describing business processes, each element of which a separate business process is, reflecting the subsystems and stages of the life cycle of the product produced; an adapted method for analyzing value chains.

For example, the value chain approach requires the submission of following tasks: identification of the company's customers and their forecast in the market; identification of priority products that customers consume, and identification of customer value for customers; identification of flows and operations, which result in the products consumed by customers of the company.

The methodology of adapted method is based on the transformation of resources into products with the required 
customer value and includes following components: representation of the processes of functioning in the form of a system of inputs and outputs of resources; the separation of business processes by main, supporting, management and development; considering the interests of participants in business processes and key interacting objects.

\section{Prepare Model of Logistic Business Chain}

Let us consider a simple type of logistic chain, creating logistic values in the form of a linear structure with a single management center (MC). Such a structure can be described for the organizational management of a hierarchical twolevel structure, the number of which is $\mathrm{N} \geq 1$, and among the participants $\left\{a_{i k}\right\}$ there is a business chain management center (MC).

We believe that $\mathrm{X}$ is the set of participants in the logistics chain, among which there is a management center, MC, which forms the objective function of activity $(\mathrm{C})$ in the form of a criterion of profitability $\mathrm{H}(\mathrm{C})$. In this chain, each participant (the active element is AE), aij interacts with other $\mathrm{AE}$ and external participants in the process of operational activity through a set of interactions $\{R\}$. In the process of operational interactions $A E\left(a_{1}, a_{2}, \ldots, a_{j}, \ldots, a_{n}\right),\left(a_{i}\{R\} a_{j}\right)$ the final product (consumer value) is formed, the effectiveness of which is determined by goal $C$ or yield $H(C)$ [15]

And since each member of the chain is an active element, it has its own operating strategy as part of the chain $\left(s\left(a_{j}\right)\right)$, consistent with the strategy of the MC $\left(s^{o}\left(s\left(a_{j}\right)\right) \in s^{o}\right) \subset\{S\}$. Each participant forms his own operating income, $h\left(a_{i}\right)$ and the level of local profitability is also determined by the effectiveness of the previous participants in the chain, $h\left(a_{i}\right)$ $=f\left(e\left(a_{i-1}\right)\right)$. According to the results of activity, each element forms the information $i\left(h\left(a_{i}\right)\right)$.

For the whole chain, in the case of the interdependence of the effect level on the preceding operations, we have the following function of composition

$$
\begin{gathered}
h\left(a_{M C}\right)=f\left(e\left(a_{1}\right) \circ e\left(a_{2}\right) \circ \ldots \circ e\left(a_{n}\right)\right), \\
\text { or } H(C)=h\left(a_{M C}\right)=f\left(e_{n}\left(e_{n-l}\left(e\left(a_{1}\right)\right) \ldots\right)\right)
\end{gathered}
$$

Earlier, we determined that the participant's profitability (efficiency) function $h\left(a_{i}\right)$ depends on the selected types of interaction of participants, $\left(a_{i} r_{j} a_{i}\right), r_{i} \in\{R\}$, where $\{R\}$ is the set of possible interactions of participants ensuring the implementation of operations in the logistics chain.

When forming variable chain structures, in accordance with possible strategies of structural organization, we assume that participants can be streamlined for selection into the chain structure, according to some priorities in creating customer value in the form of a ranked list, for example, $a_{1} \leq$ $a_{2} \leq \ldots \leq a_{n}$.

The most important participant is the one that has higher priority (lower rank) in an ordered sequence $\left(a_{1}\right)$. The priority of the participant can be influenced by the content of information $i\left(h\left(a_{i}\right)\right)$. In this case, one can determine the information priority in the following scheme: $i\left(h\left(a_{1}\right)\right) \leq$ $i\left(h\left(a_{2}\right)\right) \leq \ldots \leq i\left(h\left(a_{n}\right)\right)$. Therefore, when forming a new chain structure, a priority participant, if the functional conditions are fulfilled, can replace the participant already existing in the business chain. Considering the factors of formation of the profitability function of the logistics chain, we define its dependence, except for the system of interactions, by other parameters:

- $\quad$ the role of the participant in the operational space of the chain, $s\left(a_{i}\right)$,

- the level of logistic resources available for the participant $a_{i},\left(P\left(a_{i}\right)\right)$,

synergy or risk in the process of interaction of the participants, which can also lead to an increase / decrease in the level of efficiency, $\Delta E_{s}$.

To assess the effectiveness of the supply chain, you can set the efficiency function (E), in this form:

$$
\begin{gathered}
E=f\left(a_{M C}\right)=\left\{f\left(s\left(a_{1}\right)\right), P\left(a_{1}\right), e\left(a_{1}\right),\left(s\left(a_{2}\right),\right.\right. \\
\left.P\left(a_{2}\right), e\left(a_{2}\right)\right), \ldots,\left(s\left(a_{n}\right), P\left(a_{n}\right), e\left(a_{n}\right)\right), \\
\left.\left\{\left(a_{i j}\right)\{R\}\left(a_{j i}\right)\right\}, i\left(h\left(a_{i}\right)\right), \Delta E_{s}\right\} .
\end{gathered}
$$

At the same time, the function of efficiency (income) $H$ is variable and depends on the level of efficiency of each participant in the logistics chain. Thus the function

$$
H\left(C\left(e_{1}, e_{2}, \ldots, e_{m}\right)\right)
$$

ensures the formation of a certain range of values of profitability from the implementation of operations by participants in the chain,

$$
H\left(C\left(e_{1}, e_{2}, \ldots, e_{m}\right) \rightarrow\left[H^{*}(C) \div H_{o}(C)\right],\right.
$$

where $H^{*}(C)$ is the marginal value of the income function $L C$, with the most optimal (best) interaction options, $H_{o}(C)$ is the minimum value of profitability in the $L C$ chain, with the initial, non-best ways of interaction between the participants in the logistics chain.

The value of return can be set as a difference of the index of the effect of the chain's activities $(H(C))$ and the total costs of all chain participants $\left(Z_{L C}\right)$ in the form

$$
\left(H \left(C\left(e_{1}, e_{2}, \ldots, e_{n}\right)-Z_{L C)}\right.\right.
$$

During the implementation of the operating activities of the chain, each participant chooses those interactions with other participants from a variety of possible, subject to resource constraints, which maximize the difference between incentives for the logistic operation $\left(\delta\left(a_{i}\right)\right)$ and its costs $z\left(r_{i}, a_{i}\right)$, $\left[\delta\left(a_{i}\right)-z\left(r_{i}, a_{i}\right)\right]$.

Since the profitability function is variable, to obtain the maximum value of the profitability of the whole chain structure, it is necessary to solve the problem

$$
\left[\delta\left(\mathrm{a}_{i}\right)-z\left(r_{i}, a_{i}\right)\right] \rightarrow \max _{s_{i} \in S} \mathrm{E}
$$

The solution of the problem is determined by the rule

$$
\operatorname{Argmax}\left[\delta\left(\mathrm{a}_{i}\right)-z\left(r_{i}, a_{i}\right)\right]
$$

The chain management policy is defined through the choice of a rational, efficient supply chain structure. At the same time, each participant will choose such incentive 
functions, which, if the participant rationally sets his own parameters of activities in the chain, get the maximum of the mathematical expectation of his objective function.

\section{TASKS OF MANAgING THE StRUCtURE OF THE SUPPLY CHAIN}

This section discusses the possible tasks of managing the supply chain composition (LC). There is no doubt that the basic efficiency of logistics chains, including international ones, depends on the objective functions and the typology of the logistics chain. An important feature of logistics chains in Industry 4.0 is the generalization of the information support of the results of the activities of each participant into a single information pool $(J)$ of a distributed type $\left(\left(i\left(h\left(a_{1}\right)\right)\right.\right.$, $i\left(h\left(a_{2}\right)\right), \ldots, i\left(h\left(a_{n}\right)\right) \subset\{J\}$.

And further, the chain structure, chain participants' consistency, logistics resources, etc. will influence the chain's efficiency. The composition and structure of the chain undoubtedly affect the overall efficiency, and in this regard, for each type of chain, it is necessary to solve the problems of LC composition and management of LC. In the paper [1] it is shown that the task of managing the composition of the chain can be reduced to the problem of optimal stimulation of the chain participants. Consider the possible formulation of the model of the logistics chain, for which we introduce the following notation.

We consider a separate logistics chain linking several participants with various operating activities. We consider the participants of the chain as active elements (AE), having their own interests and possessing some required amount of logistic resources, the number of which is $\mathrm{N}$.

To achieve the objective function of operating the logistics chain, $C(L C)$, it is possible to form several variants of the chain structure, including different participants with different operational and resource capabilities. And it is quite possible that one or several variants of the chain structure can have maximum efficiency $\left(E_{\max }\right)$.

Consider the task of managing the structure of the logistics chain. If $I_{0}=\{1,2, \ldots, N\}$ is the actual (initial) composition of the chain $L C$, consisting of $N$ participants of $A E,\left|I_{0}\right|=N>1 . I_{E}$ is the final, most effective composition of the $L C$ chain, which is the result of solving the task of composition management, $I_{E} \rightarrow \max E$. $\mathrm{M}-$ initial set of potential (actual and possible bidders) participants in the supply chain $L C, N \subseteq M$.

The following types of chain structure management exist.

1.If the following condition is satisfied $I_{o} \subseteq I_{E} \subseteq M$, then the management task is reduced to expanding the original structure.

2.If the condition is met $I_{E} \subseteq I_{o} \subseteq M$, then the task of the management of diversification (separation from the structure) of the chain participants is performed.

3.If the condition is met $I_{o} \approx I_{E} \approx N$, (the content characteristic of the chain changes, with a permanent structure - replacing one participant with another with more efficient operations), then the management task of replacing participants is performed.
Characteristics of the degree of integration and diversification can be estimated through the ratio of performance indicators of the initial and the target structure of the supply chain as an increment of efficiency $\Delta \mathrm{E}$,

$$
\Delta E=\left(E\left(I_{E}\right)-E\left(I_{0}\right)\right) E\left(I_{0}\right)
$$

The task of managing the chain structure of the $L C$ requires the development of a chain management process that ensures maximum efficiency of the logistics process $\left(E_{\max }\right)$. The task of forming the logistic chain structure can be formulated as the task of finding such an admissible $L C$ structure on the set of possible variable chains of the $\left\{L C_{i j}\right\}$ structure, for which the chain efficiency $(E)$ would be maximum, with restrictions on the functional composition of participants in the chain structure $\left(F_{j}^{i} \geq F_{j}^{k}\right)$ and the level of economic potential of the chain participants $\left(P_{j}^{i} \geq P_{j}^{k}\right)$.

$$
E\left(P,\left\{L C_{i j}\right\}, I_{0}, I_{E}, M, N\right) \rightarrow \max
$$

under restrictions $\left(F_{j}^{i} \geq F_{j}^{k}\right),\left(P_{j}^{i} \geq P_{j}^{k}\right)$.

We believe that each potential participant in the logistics chain $i \subseteq M$ should have capital, competencies, logistics resources and other parameters for activities in the logistics value chain. At the same time, we believe that there is a unified policy for managing the composition of the chain, which should include the following elements:

the presence of common development goals by participants of the chain;

- priority of common goals over their own goals of activity among participants; by participants;

coordination of operational processes in the chain

- $\quad$ the possibility of integration of individual members of logistics resources;

ensuring a balance of interests of the participants in the logistics chain.

\section{CONCLUSION}

The paper considers the tasks of modeling and forming an effective structure of logistic value chains in the Arctic zone. The Arctic has many critical features that should be considered when forming economic systems of production, mining and service types there. A review of approaches to modeling business chains is given their systematization according to typology and characteristics is given. Considering the features of the Arctic zone and international interest in this zone not only for circumpolar countries but also for other states, it is proposed to consider the Arctic economic zone as an international corporate economic zone with a system of international corporations, within which chains and value networks are formed, including areas of production, mining, logistics, ecology, social sphere, etc.

The task of forming a generalized model of the logistics chain is considered, its parameters are described, and a function of the efficiency of the business chain is formed considering the local effectiveness of the participants. To obtain the maximum level of efficiency, the task of managing the structure of the logistics chain is formed and determined, which allows participants to vary in terms of their 
functionality, resources and level of local efficiency, taking into account the synergy of interaction in the chain structure.

\section{REFERENCES}

[1] Zaychenko, I.M., Ilin, I.V., Lyovina, A.I. Enterprise architecture as a means of digital transformation of mining enterprises in the Arctic (2018) pp. 4652-4659.

[2] Balashova, E.S., Gromova, E.A. Arctic shelf development as a driver of the progress of the Russian energy system (2017) 106, 06008.

[3] Karlin, L.N., Gogoberidze, G.G., Abramov, V.M., Golosovskaya, V.A. On route to Integrated Water Resources Management for Russian arctic and subarctic rivers / International Multidisciplinary Scientific GeoConference Surveying Geology and Mining Ecology Management, SGEM. (2014).

[4] Zaychenko, I.M., Ilin, I.V., Dubgorn, A. Using business model as a tool of Arctic region medicine strategic development (2018) pp. 53135319.

[5] Kikkas, K., Romashkina, E. Potential Opportunities for the Arctic Transport Space (2018) 180 (1), 012016.

[6] Kozmenko, S., Teslya, A., Fedoseev, S. Maritime economics of the Arctic: Legal regulation of environmental monitoring (2018) 180 (1), 012009.

[7] A.P. Karavaev Uniform Stimulation Systems Volume 64, Issue 1 , January 2003, Pages 104-137 Automation and Remote Control

[8] D.L.M. Nascimento, V. Alencastro, O.L.G. Quelhas, R.G.G. Caiado, J.A. Garza-Reyes, L.R. Lona, G. Tortorella Exploring Industry 4.0 technologies to enable circular economy practices in a manufacturing context: A business model proposal (2019) Journal of Manufacturing Technology Management.
[9] E.A. Afonichkina, A.I. Afonichkin Synergies of the Economic Development of the Arctic Cluster System IOP Conference Series: Earth and Environmental Science Volume 180, Issue 1, 10 August 2018

[10] J. Wang, H., Sii J.B. Yang, A. Pillay, D. Yu, J. Liu, E. Maistralis, A. Saajedi Use of advances in technology for maritime risk assessment // Risk analysis. 2004. Vol. 24. P. 1041-1063.

[11] J.J. Dell, P. Pasteris Adaptation in the oil and gas industry to projected impacts of climate change // Proceedings of the SPE International Conference on Health, Safety and Environment in Oil and Gas Exploration and Production, 12-14 April 2010, Rio de Janeiro, Brazil.

[12] M. E. Porter, M. R. Kramer Strategy and Society: The Link Between Competitive Advantage and Corporate Social Responsibility// Harvard Business Review, December 2006.

[13] M.D. Mathews General economics systems stability states and negative synergy(2007) International Advances in Economic Research, 13 (2), p. 254.

[14] N. I. Didenko, D. F. Skripnuk, K. N. Kikkas, V. Merkulov, G. Romashkin, S. V Kulik.. The analysis of convergence - Divergence in the development of innovative and technological processes in the countries of the Arctic Council, pp. 626-631.

[15] Gogoberidze, G.G., Karlin, L.N., Abramo,v V.M., Lednova, J.A., Malakhova, J.A. Marine economic potential assessment for environmental management in the Russian Arctic and subarctic coastal regions / International Multidisciplinary Scientific GeoConference Surveying Geology and Mining Ecology Management, SGEM. (2014).

[16] Summary of the Key Findings from the UK Climate Change Risk Assessment 2012. DEFRA, UK, 2012. 